\title{
Multiple Shoot Induction from Immature Inflorescence in Sorghum
}

\author{
N. Sarada Mani* and Sudhakar R. Pola \\ Department of Botany, Andhra University, Visakhapatnam-530 003, India \\ Received April 16, 2003; accepted May 3, 2003
}

\begin{abstract}
Summary Three improved varieties of Sorghum bicolor (L) Moench SPV 475, CSV 13 and CSV 15 were studied for the regeneration and multiple shoot induction. Explants of young immature inflorescence were cultured on modified Murashige and Skoog medium supplemented with $2 \%$ sucrose, $0.8 \%$ agar and $1.5 \mathrm{mg} / 1$ 2,4-D for callus initiation. Within 9 to $11 \mathrm{~d}$ callus initiation was observed. During third week 2 types of calli were identified, one was white compact, nodular embryogenic callus, while the other was unorganized, non morphogenic and non embryogenic callus. After transferring the callus onto regeneration medium (MS+BAP), somatic embryos were formed, shoot initiation was observed from somatic embryos and was maximum at $1 \mathrm{mg} / 1$ BAP (7-17 shoots per culture). For multiple shoot induction different combinations of plant growth regulators $(\mathrm{MS}+\mathrm{BAP}+2,4-\mathrm{D}, \mathrm{MS}+\mathrm{GA}+\mathrm{NAA}, \mathrm{MS}+\mathrm{BAP}+\mathrm{IAA}, \mathrm{MS}+\mathrm{BAP}+\mathrm{GA})$ along with asparagine and proline $(50 \mathrm{mg} / \mathrm{l})$, were used. Among these combinations $\mathrm{MS}+1 \mathrm{mg} / \mathrm{l} \mathrm{BAP}+1 \mathrm{mg} / \mathrm{l}$ IAA gave maximum shoot induction. In this combination about 11-69 shoots were obtained per culture. And subsequent root formation was obtained with half strength MS $+1.0 \mathrm{mg} / 1 \mathrm{NAA}$.
\end{abstract}

Key words Sorghum, Immature inflorescence, 2,4-D, Embryogenic callus, 6-benzylaminopurine (BAP), IAA, Multiple shoots.

Sorghum is one of the important cereal crops in the world. It is well adapted with too little rainfall areas and it is a major food and lives stock feed crop in many parts of Asia and America. It is a major dryland cereal grown as food crop for humans feed and fodder for animals. It represents about $30 \%$ of world acreage and $83 \%$ in south East Asia. Sorghum is grown during the rainy season in 7 million ha as well as winter season in 5.6 million ha (Rana et al. 1998). Due to high starch content in sweet Sorghum it is widely used in alcohol industry. In addition to its principle uses as flour preparation of porridge and unleavened bread. Species of this genus are sources of grain, fiber, fuel and secondary products. In some Sorghum varieties, fiber and cellulose are suitable for the paper making industries.

Previously in S. bicolor the different explants used for in vitro studies include embryos (Gamborg et al. 1977), mature and immature embryo, seedling tissue, leaf sheath and immature inflorescence (Bhat and Kuruvinashetti 1993). Much more scientists recommended immature inflorescence as potential explants for high regeneration (Bhat and Kuruvinashetti 1993, Elkonin and Pakhomova 1996, George et al. 1989, Rao et al. 2000).

New approaches are available to the geneticists and plant breeders with in vitro methods for exploitation of selection of the desired traits at the cellular level. Though it is easy to establish cell or callus cultures in most cereal crop species, regeneration of plants from these cultures is often difficult (Vasil and Vasil 1987). Low level of regeneration response in cereals including Sorghum bicolor (L) Moench is associated with genotype specificity and gradual loss of regeneration ability (George et al. 1989, Cai and Butler 1990). Therefore a reproducible protocol for efficient plant regeneration from established callus or cell cultures is needed in Sorghum. A series of trails were conducted in the present study for multiple shoot induction, in view of their importance in crop im-

\footnotetext{
* Corresponding author, e-mail: nsaradamani@rediffmail.com.
} 
provement programmes.

\section{Materials and methods}

Seeds of Sorghum bicolor (L) Moench. Genotype of SPV 475, CSV 13 and CSV 112 were obtained from N.R.C.S, Hyderabad, A.P. India, and raised in the experimental farms of Botany Dept, Andhra University, Visakhapatnam, India. After $60 \mathrm{~d}$ of sowing the inflorescence was taken for further experiment. Young immature inflorescence size ranging from $3-5 \mathrm{~cm}$ and clear visibility at the branch primordia in the lower half of the inflorescence and having pinhead size spikelets on the surface of these genotypes were used as the source material for callus initiation. Of the several factors influencing the callus formation and regeneration of plantlets the developmental stage of the inflorescence is of considerable importance in Sorghum. Our earlier investigations on the impact of different stages of inflorescence in callus formation have reveled better response of the explants from young immature inflorescence only. Hence they were used as explants in all these studies. Before inoculating the explant the panicle must be kept under running tap water for $30 \mathrm{~min}$ to $1 \mathrm{~h}$. After removing the leaves the panicle was washed with distilled water for 2 to 3 times, after that it was dipped in $0.1 \% \mathrm{HgCl}_{2}$ solution for $1 \mathrm{~min}$ to remove bacterial and fungal contamination. Then the panicle was washed with distilled water for 2 to 3 times. The explants were cultured on $20 \mathrm{ml}$ of MS medium (Murashige and Skoog 1962). The analysis of the influence of the nature and concentration of growth substances was carried out after a preliminary study of the impact of explant size, genotype, nature of donar organ and level of excision. As the percent of explants forming callus decreased with the increase or decrease in explant size, we have taken $0.5 \mathrm{~cm}$ as standard size for explant inoculation. Before that the inflorescence was taken out by giving a vertical insertion through the surrounding leaf sheath and was then cut into pieces of 2-12 segments. The medium was adjusted to $\mathrm{pH} 5.8$ prior to autoclaving, solidified with $0.8 \%$ agar and medium was autoclaved at $15 \mathrm{LB}$ (pressure), $120^{\circ} \mathrm{C}$ for $20 \mathrm{~min}$.

Cultures were incubated at $25 \pm 2{ }^{\circ} \mathrm{C}$ in dark conditions for callusing. Six weeks old embryogenic totipotent callus cut into nearly equal size were transferred on to modified MS media supplemented with BAP, $16 \mathrm{~h}$ light was provided with cool white fluorescent light. Regenerated plantlets were transplanted into soil and grown to maturity in a glass house. Embryogenic callus cultured with cut surfaces touching the medium.

\section{Results and discussions}

Within $9 \mathrm{~d}$ after inoculation we have observed callus initiation from the cut ends of the explant. By the end of 2nd week callus grows luxuriantly, and from 3rd week onwards we could distinguish embryogenic callus (EC) from non-embryogenic (NC) callus based on their colour and compactness. The EC was white, compact, with smooth shiny surface and nodular in nature (Fig. 1a) where as the NC callus was pale or dull creamy, soft, loosely packed and friable with a short life span. For callus induction 2,4-D at 0.5 to $2.5 \mathrm{mg} / \mathrm{l}$ concentration was used and differential callusing ability was observed at different concentrations with maximum production at $1.5 \mathrm{mg} / \mathrm{l}$ in the 3 varieties. Hence the further studies on multiple shoot induction were confined to this concentration alone.

The white EC after transferring to regeneration medium containing BAP $1 \mathrm{mg} / \mathrm{l}$, somatic embryos were formed had gradually changed from white to green colour shoot buds. Then shoot buds were proliferated to form shoots (Fig. 1b) within 6-18 d. Shoot number was increased with gradual increase of 2,4-D in the callus initiating medium (Table 1). The level of cytokinin used for plant regeneration appeared to be critical in producing normal vigorous shoots in large numbers. Initially for regeneration different concentrations of BAP were used $(0.25-1.25 \mathrm{mg} / \mathrm{l})$, but shoot formation was optimum at $1 \mathrm{mg} / \mathrm{l}$ concentration. Plant regeneration can be further improved by exposing the 


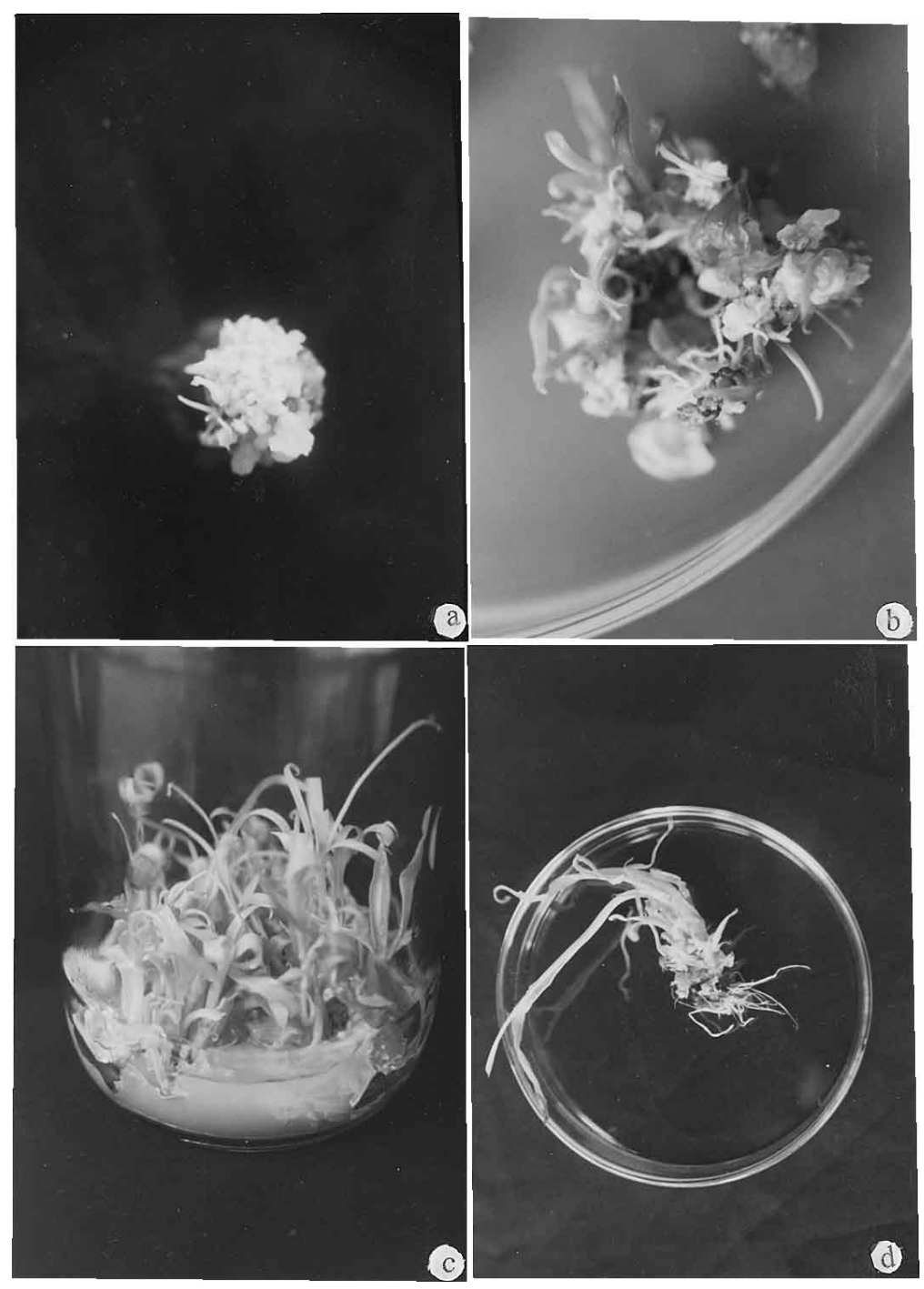

Fig. 1. a) embryogenic callus from immature inflorescence, b) shoot initiation from embryogenic callus, c) multiple shoots on MS + BAP $(1 \mathrm{mg} / \mathrm{l})+\mathrm{IAA}(1 \mathrm{mg} / \mathrm{l})$, d) multiple shoots with roots on MS + NAA $(1 \mathrm{mg} / \mathrm{l})$.

organized callus to low levels of cytokinins. Shoot buds and somatic embryos were distinguished on the basis of open buds firmly attached to the callus in the former and bipolar structures as well as globular bodies loosely associated with callus in the latter. Somatic embryos were found in more numbers compared to shoot buds.

Variety SPV 475 was more responsive at 1.0 and $1.5 \mathrm{mg} / \mathrm{l}$ initial concentration of 2,4-D, $1 \mathrm{mg} / \mathrm{l}$ of BAP i.e. 156 and 174. In CSV 13 maximum shoots are obtained at 1.0 and $1.5 \mathrm{mg} / 1$ of 2,4-D and $1 \mathrm{mg} / \mathrm{l}$ of BAP it was 135 and 143. Whereas in CSV 112 maximum number of shoots were obtained at 1.0 and $1.5 \mathrm{mg} / \mathrm{l}$ of 2,4-D and $1 \mathrm{mg} / \mathrm{l}$ of BAP it was 105 and 120 (Table 1). Elongated and welldeveloped shoots were transferred to rooting media containing NAA at $1.0 \mathrm{mg} / \mathrm{l}$. Root initiation was observed within 9-12 d after culture. When medium contained BAP only the plantlets ranged from 7-17 in a single culture in SPV 475, 8-14 in CSV 13 and 7-12 in CSV 112 but combination of BAP with IAA produced more number of plantlets. Maximum number of multiple shoots were ob- 
Table 1. Regenerated shoot and root number in Sorghum

\begin{tabular}{|c|c|c|c|c|}
\hline \multirow{2}{*}{ Inbred line } & \multirow{2}{*}{$\begin{array}{l}\text { Initial 2,4-D concentration } \\
\text { used for callus induction } \\
\qquad(\mathrm{mg} / \mathrm{l})\end{array}$} & \multicolumn{2}{|c|}{ No. of regenerated shoots } & \multirow{2}{*}{$\begin{array}{l}\text { No. of root } \\
\mathrm{MS}+\mathrm{NAA}\end{array}$} \\
\hline & & MS only & $\mathrm{MS}+\mathrm{BAP}$ & \\
\hline \multirow[t]{5}{*}{ SPV 475} & 0.5 & 0 & $9(89)$ & 17 (173) \\
\hline & 1.0 & $2(21)$ & $16(156)$ & $33(335)$ \\
\hline & 1.5 & $2(23)$ & $17(174)$ & 34 (339) \\
\hline & 2.0 & 2 (19) & $11(107)$ & $23(234)$ \\
\hline & 2.5 & 0 & $7(73)$ & 15 (153) \\
\hline \multirow[t]{5}{*}{ CSV 13} & 0.5 & 0 & 13 (133) & 25 (249) \\
\hline & 1.0 & $1(11)$ & $13(135)$ & $25(254)$ \\
\hline & 1.5 & $2(11)$ & $14(143)$ & $26(261)$ \\
\hline & 2.0 & $1(10)$ & $11(110)$ & $21(211)$ \\
\hline & 2.5 & 0 & $8(82)$ & 15 (147) \\
\hline \multirow[t]{5}{*}{ CSV 112} & 0.5 & 0 & $8(76)$ & $17(173)$ \\
\hline & 1.0 & 0 & $10(105)$ & $21(212)$ \\
\hline & 1.5 & $1(9)$ & $12(120)$ & $25(253)$ \\
\hline & 2.0 & 0 & $9(91)$ & $17(171)$ \\
\hline & 2.5 & 0 & $7(73)$ & $13(130)$ \\
\hline
\end{tabular}

Average values rounded off to the nearest whole number. Values in brackets indicate total number of shoots obtained from 10 cultures.

Table 2. Multiple shoot induction per culture

\begin{tabular}{|c|c|c|c|c|c|c|}
\hline \multirow{2}{*}{ Inbred line } & \multicolumn{6}{|c|}{$\mathrm{MS}+1 \mathrm{mg} / 1 \mathrm{IAA}+\mathrm{BAP}$ concentrations mg/l } \\
\hline & 0.25 & 0.50 & 0.75 & 1.0 & 1.25 & 1.50 \\
\hline \multicolumn{7}{|l|}{ SPV 475} \\
\hline Shoot No. & $20(204)$ & $36(362)$ & $58(581)$ & $69(691)$ & $67(675)$ & $36(364)$ \\
\hline Root No.* & $41(412)$ & $78(779)$ & $126(1262)$ & $141(1415)$ & 139 (1392) & $70(704)$ \\
\hline \multicolumn{7}{|l|}{ CSV 13} \\
\hline Shoot No. & 19 (197) & $29(293)$ & $41(407)$ & $63(634)$ & 37 (372) & $16(162)$ \\
\hline Root No.* & $34(343)$ & $63(635)$ & $73(735)$ & $127(1270)$ & $80(805)$ & $30(302)$ \\
\hline \multicolumn{7}{|l|}{ CSV 112} \\
\hline Shoot No. & $12(123)$ & $17(170)$ & $30(301)$ & $30(305)$ & $23(231)$ & $11(113)$ \\
\hline Root No.* & $22(224)$ & 33 (332) & $60(603)$ & $61(614)$ & 43 (432) & $23(230)$ \\
\hline
\end{tabular}

No. of regenerants per culture adjusted to nearest figures. Figures in brackets indicate total number of regenerants per 10 cultures.

* Rooting medium was MS $+1 \mathrm{mg} / 1$ NAA.

served in SPV 475 (Table 2 and Fig. 1c). Addition of BAP with IAA at $1.0 \mathrm{mg} / \mathrm{l}$ enhances multiple shoot formation. Presence of IAA in the regeneration medium generally has positive influence on plant regeneration. In embryogenesis BAP significantly stimulated the regeneration of plant in the presence of IAA. The number of shoots produced per explant varied with the genotypes and maximum number of shoots were observed at $1 \mathrm{mg} / 1$ BAP with $1.0 \mathrm{mg} / 1$ of IAA ( $691 / 10$ cultures in SPV 475). Shoot number was increased with gradual increase of BAP concentration from 0.25 to $1.0 \mathrm{mg} / \mathrm{l}$ after $1.0 \mathrm{mg} / \mathrm{l}$ the shoot number was decreased (Table 2 ).

Significant correlation $(p<0.05)$ was observed in multiple shoot induction, which was dependent on genotype as well as conc. of BAP (Table 3 ).

Shoot lengths were measures at the end of every 3 week from 3rd to 9th week. Shoot lengths were increased with increasing the age of the shoots. (Table 4). The length of shoot was proportional to the age of shoots and it was more in CSV 13. 
Table 3. ANOVA test

\begin{tabular}{lcccc}
\hline \hline Sources of variance & DF & SS & MS & $F$ value \\
\hline BAP concentration & $6-1=5$ & 5574 & 1114.8 & $11.33^{*}$ \\
Genotype & $3-1=2$ & 2864.33 & 1432.2 & $14.56^{*}$ \\
Error & 10 & 983.67 & 98.37 & \\
\hline Total & $18-1=17$ & 9422.00 & & \\
\hline
\end{tabular}

$* F$ value significant at $p=0.05$.

Table 4. Shoot lengths $(\mathrm{cm})$

\begin{tabular}{llll}
\hline \hline Inbred line & 3rd week & 6th week & 9th week \\
\hline SPV 475 & $1.59 \pm 0.04$ & $3.52 \pm 0.02$ & $6.28 \pm 0.03$ \\
CSV 13 & $1.46 \pm 0.05$ & $2.93 \pm 0.03$ & $7.18 \pm 0.06$ \\
CSV112 & $1.12 \pm 0.02$ & $2.43 \pm 0.09$ & $4.46 \pm 0.11$ \\
\hline
\end{tabular}

\pm Values indicate standard error.

When the plantlets were $3 \mathrm{~cm}$ long, they were transferred to the rooting medium containing $1.0 \mathrm{mg} / 1$ NAA. Preliminarily we have tested with different growth regulators of 2,4-D, IAA, IBA and NAA, where we observed best performance with NAA only; hence we continued our experiment with NAA only. In addition low level of sucrose in the medium and 1/2 strength medium was found to favorable for rooting. Shoots after transferring on to the rooting medium, root initiation started within 9 to $12 \mathrm{~d}$ and it was depended on shoot number (Tables 1,2). A maximum of 1415 roots per 10 cultures was observed in SPV 475. 9-week old well root established plants were initially established in polyethene bags $(4 \times 8 \mathrm{~cm}$ size $)$ and then reestablished in large earthen pots for further growth and maturity. This process was undertaken in a growth room after 2 to 3 weeks the plantlets are transferred to pots at greenhouse. The potting mixture consisted of good quality farmyard manure, river sand and clay soil $(1: 2: 1)$. The growth of the established plantlets in pots was slow at initial stage. Half of this period under shade and then moved to the field under standard cropping conditions.

Kresovich et al. (1986) reported multiple shoots in sweet Sorghum but it was obtained less than 10 only. So we attempt to obtain more shoots with media manipulation and using different concentrations of growth regulators. Mythili et al. (2001) found the development of embryo-like structures from the inflorescence of about 4-6 cm in length whereas in this study $3-5 \mathrm{~cm}$ were used.

Rao et al. (1995) reported enhanced regeneration of grain and sweet Sorghum with asparagine, proline and cefotaxime. George et al. (1989) obtained high number of plantlets with high concentration of kinetin or BAP. Kuruvinashetti et al. (1998) achieved high plant regeneration using 0.75$1.0 \mathrm{mg} / \mathrm{l}$ of BAP. The level of cytokinin used for plant regeneration appeared to be critical in producing multiple shoots and suitable combination of NAA with MS medium was promising for root formation in Sorghum. Sahoo et al. (2000) studied interaction of BAP with IAA $(5: 0.5)$ for multiple shoot induction in cowpea. He reported $100 \%$ regeneration. Venkatachalam et al. (2000) obtained high number of shoots using with the combination of BAP, 2,4-D and NAA in rice. Whereas in the present study 11-69 multiple shoots are obtained with combination of BAP and IAA at $1.0 \mathrm{mg} / \mathrm{l}$ concentration and are high in the variety SPV 475.

In view of the importance of induction of multiple shoots in Sorghum for their use in transgenic and genetic engineering it can be achieved by selecting suitable source material, culture maintenance, temperature, light and hormonal manipulation in a positive direction. The level of 
auxins + cytokinin combination and use of asparagine and proline enhanced the multiple shoot induction.

\section{Acknowledgements}

The authors acknowledges the financial assistance from University Grants Commission, New Delhi, India and NRCS, Hyderabad, India for the supply of seeds.

\section{References}

Bhat, S. and Kuruvinashetti, M. S. 1993. Differential in vitro response of male sterile line A296 and it's maintainer. Sorghum Newsletter 34: 31.

Cai, T. and Butler, L .1990. Plant regeneration from embryogenic callus initiated from immature inflorescence of several high tanin Sorghums. Plant Cell Tiss. Org. Cult. 20: 101-110.

Elkonin, L. A. and Pakhomova, N. V. 1996. Influence of $\mathrm{N}_{2}$ sources on induction and growth of embryogenic callus of Sorghum. Sorghum Newsletter 37: 68-69.

Gamborg, O. L., Shyluk, J. P., Brar, D. S. and Constabel, F. 1977. Morphogenesis and plant regeneration from callus of immature embryos of Sorghum. Plant Sci. Lett. 10: 67-74.

George, L., Eapen, S. and Rao, P. S. 1989. High frequency somatic embryogenesis and plant regeneration from immature inflorescence culture of two Indian cultivators of Sorghum bicolor (L.) Moench. Proc. Indian Acad. Sci., Plant Sci. 99: 405-410.

Kresovich, S., McGee, R. E. and Wadsworth, S. J. 1986. In vitro genotypic responses of sweet Sorghum to the synthetic auxins. Sorghum Newsletter 29: 94-96.

Kuruvinashetti, M. S., Patil, V. M., Sumangala, B. and Maheshwar, H. 1998. High frequency plant regeneration from embryogenic callus cultures in genus Sorghum. Indian J. Agri. Sci. 68: 27-28.

Murashige, T. and Skoog, F. 1962. A revised medium for rapid growth and bioassays with tobacco tissue cultures. Physiol. Plant. 15: 473-497.

Mythili, P. K., Reddy, V. D. and Seetharam, N. 2001. Regeneration and analysis of genetic variability in wild Sorghum, S. australiense graber and snyder. Cytologia 66: 341-348.

Rana, B. S., Singh, B. U., Rao, M. H., Indira, S., Rao, S. S. and Kaul, S. L. 1998. Sorghum research in India. Indian J. Agri. Sci. 68: 405-422.

Rao, A. M., Padmasree, K. and Kishor, P. B. K. 1995. Enhanced plant regeneration in grain and sweet Sorghum by asparagine, proline and cefotaxime. Plant Cell Rep. 15: 72-75.

Rao, R. V. R., Pavankumar, G., Subba Rao, M. V. and Manga, V. 2000. Differential in vitro response of genotypes of Sorghum. Phytomorphol. 50: 253-260.

Sahoo, L., Sushma, T. S., Dolendro, S. N. and Pawan, K. J. 2000. In vitro plant regeneration and recovery of cowpea (Vigna Unguiculata) transformants via Agrobacterium mediated transformation. Plant Cell Biotech. Mol. Biol. 1: 47-54.

Vasil, I. K. and Vasil, V. 1987. Regeneration in Cereal and Other Grass Species. In: Cell Culture and Somatic Genetics of Plants. pp. 150-212.

Venkatachalam, P., Geetha, N., Priya, P., Rajasegar, G. and Jayabalan, N. 2000. Efficient callus induction and plant regeneration from immature anthers of rice (Oryza sativa L.) via somatic embryogenesis. Plant Cell Biotech. Mol. Biol. 1: $55-62$. 